\title{
Correction to: Business Information Systems
}

\author{
Witold Abramowicz (1) and Rafael Corchuelo (1)
}

\section{Correction to: \\ W. Abramowicz and R. Corchuelo (Eds.): \\ Business Information Systems, LNBIP 353, https://doi.org/10.1007/978-3-030-20485-3}

In Chapter "Time Series Forecasting by Recommendation: An Empirical Analysis on Amazon Marketplace":

The original version of this chapter was previously published as non-open access. It has now been changed to open access under a CC BY 4.0 license and the copyright holder is now 'The Author(s).' The correction to the book has been updated with the change.

In Chapter "A DMN-Based Method for Context-Aware Business Process Modeling Towards Process Variability":

In the originally published version of chapter 14 , a link to reference 12 was missing in two places. This has been corrected.

The updated version of these chapters can be found at https://doi.org/10.1007/978-3-030-20485-3_4

https://doi.org/10.1007/978-3-030-20485-3_14 